\title{
Pharmacological Values and Phytochemical Properties of Devil's Cotton (Ulatkambal) - A Review
}

\section{Nargis Sultana Chowdhury ${ }^{1}$, Farhana Farjana ${ }^{1}$, Sifat Jamaly ${ }^{1}$, Mst. Nadira Begum ${ }^{2}$ and Mst. Elina Akhter Zenat ${ }^{2}$}

\author{
${ }^{1}$ Department of Pharmacy, Manarat International University, Khagan, Savar, Dhaka, Bangladesh \\ ${ }^{2}$ Biological Research Division, BCSIR Laboratories, Dhaka, Dr. Qudrat-I-Khuda Road, Dhanmondi \\ Dhaka, Bangladesh
}

(Received: November 1, 2018; Accepted: January 10, 2019; Published: January 17, 2019)

\begin{abstract}
Devil's cotton (Ulatkambal) is a genus in the family Malvaceae, with one or two species from Asia and Australia. Literature review revealed that Abroma augusta (Devil's cotton) is widely used in Ayurvedic medicine as a popular drug. Devil's cotton has been claimed to possess major biological activities like anti-diabetic, analgesic, anti-inflamatory, thrombolytic, antioxidant, hypolipidemic etc. They are also utilized by the traditional local healers of different Asian countries to treat various diseases like diabetes mellitus, as uterine tonic in emmerogogue, dysmenorrhea, amenorrhoea, sterility and other menstrual disorders, rheumatic pains of joints and headache with sinusitis. Biochemical profiling of different parts of the plant demonstrated the presence of some important phytochemicals like alkaloids, abromin, sterol, friedelin, abromasterol, taroxerylacetate, taraxeral and $\beta$-sitosterol. The aim of this review was to analyze the published report based on the medicinal values of Devil's cotton species as well to provide the updated information about the ethnomedicinal, pharmacological as well as the phytochemical properties.
\end{abstract}

Key words: Devil's cotton, Ulatkambal, Abroma augusta, Phytochemical properties, Pharmacological values.

\section{Introduction}

Many of modern drugs, vital drugs and processed medicines are of plant origin. Medicinal plants play a leading role in the treatment of varieties of human diseases from the past of human development (Bhuiya et al., 2013). Devil's cotton (Ulatkambal) is a genus in the family Malvaceae, with one or two species from Asia and Australia. The plant is evergreen, large, spreading, quick growing hairy shrub or a small tree with velvety branches found in tropical Asia, South and eastern Africa and Australia. It is a found in both wild and cultivated throughout the hot and moister parts of Bangladesh, India from Panjab and Uttar Pradesh to Arunachal Prodesh, Assam, Meghalaya and Tripura (Malek et at., 2016). It is also found (native or entlivated) throughout the worm area of India such as Sikkim,
Khasi Hills, Java, Philippines and China. (Rahman et al., 2016). Traditional herbal medicines have been attracting a great attention as alternative and supplemental therapies (Islam et al., 2012). Devil's cotton is used in diabetes mellitus, as antioxidant, uterine tonic and an emmenagogue, dysmenorrhea, amenorrhoea, sterility and other menstrual disorder, rheumatic pains of joints and headache with sinusitis (Kuadkaew et al., 2010). It is used in the management of diabetes mellitus type-2 (Islam et al., 2012). It is very popular among Thai Muslim people in three southern provinces of Thailand, since Ulatkambal seed oil has been used for treatment of pain (Kuadkaew et al., 2010).

\section{Scientific classification}

Kindom : Plantae

Correspondence to: Nargis Sultana Chowdhury; E-mail: nscmiu @gmail.com; Phone: +8801817048921 


$\begin{array}{ll}\text { Division } & \text { : Tracheophyta } \\ \text { Class } & : \text { Magnoliopsida } \\ \text { Order } & : \text { Malvales } \\ \text { Family } & : \text { Malvaceae } \\ \text { Genus } & : \text { Abroma } \\ \text { Species } & : \text { A. augusta } \\ \text { Binomial name } & : \text { Abroma augusta }(\mathrm{L.})\end{array}$

Morphological properties: Ulatkambal is a shrub or small tree about 2 to 3 meters in height (Figure 1). The leaves are alternate, ovate, 10 to 15 centimeters in length and 10 to 12 centimeters in width with pointed tip, heart-shaped base, and toothed margins. The flowers are bisexual, about 5 centimeters across and deep red or yellowish with purple bases. The fruit (capsule) is obpyramidal about 3.5 centimeters in diameter, covered with irritating hairs, and ultimately smooth, with five prominent angles or wings, which are 4 by 7 centimeters across. The seeds are subellipsoid, numerous and finely punctuate (Kuadkaew et al., 2010).
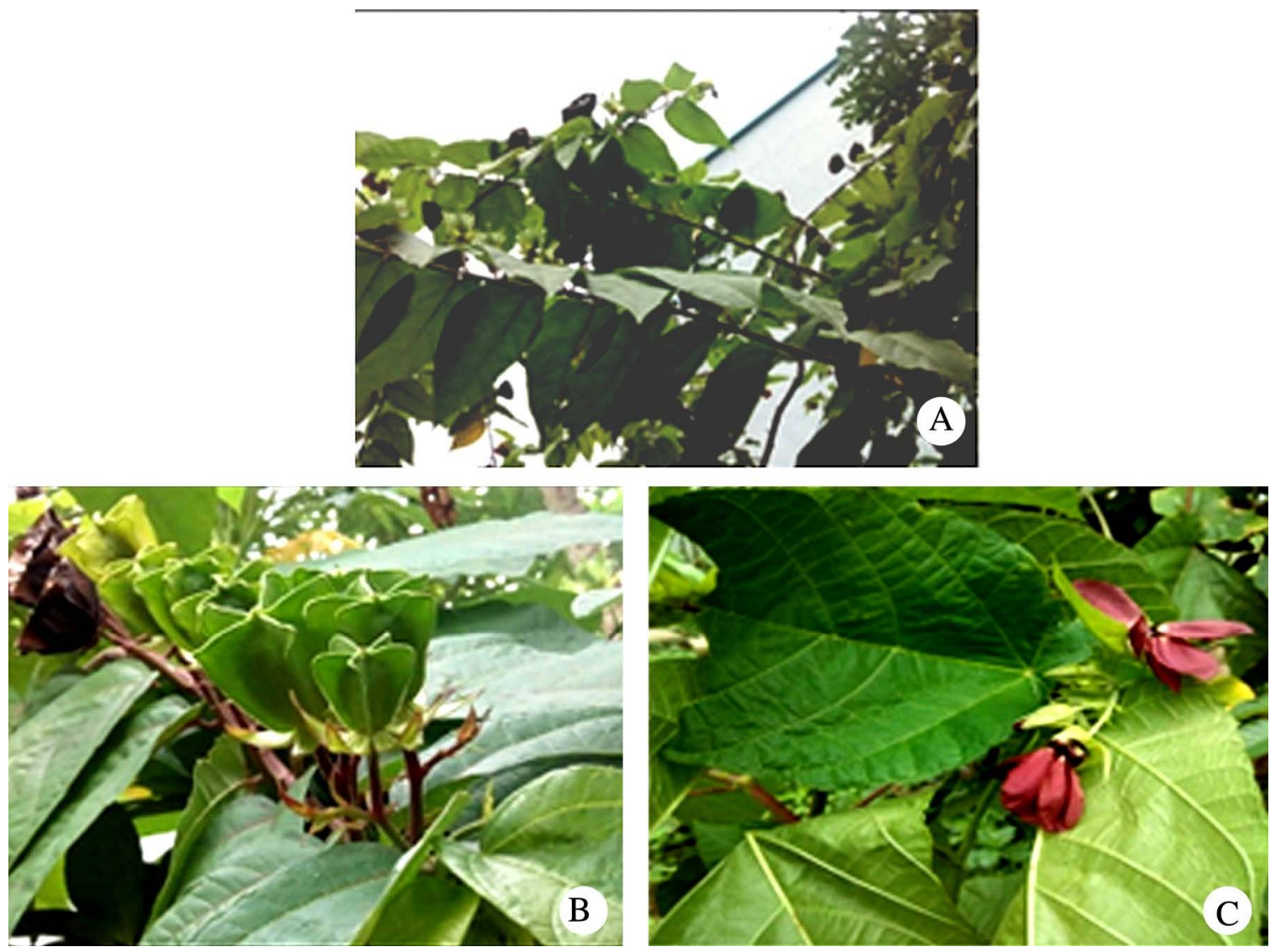

Figure 1. Morphological parts of Abroma augusta (Devil's cotton). (A) Devil's cotton plant, (B) Fruits of devil's cotton, (C) Flowers and leaves of devil's cotton.

\section{Chemical constituents or phytochemistry}

Primarily the plants consist of alkaloids. The root bark of the plant has the following constituents mixed oils, resins, alkaloids and in minute quantities water soluble base. The roots contain abromine, friedelin, abromasterol, choline, betaine, $\beta$-sitoterol, stigmasterol, a basic compound and a fixed oil. Maslinic acid and $\alpha$-amyrin have been isolated from root bark. Protocalechuic, vanillic, caffeic acid and polysaccharide fraction containing rhamanose, arabinose, xylose, mannose, galactose, glucose, galacturonic acid and glucuronic acid and acidic 
polysaccharide containing rhamnose, galacturonic acid, glucuronic acid have been reported from root<smiles>OC1CCC2C(CCC3C4CCCC4CCC23)C1</smiles>

Sterol<smiles>O=C(O)/C=C/c1ccc(O)c(O)c1</smiles>

Caffeic acid<smiles>O=C(O)c1ccc(O)c(O)c1</smiles>

Protocatechuric Acid

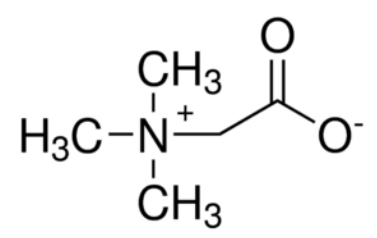

Betain bark and partially characterized (Rastogi et al., 1990, Dasgupta et al., 1970, Nahar et al., 1994)

The chemical constituents are shown in figure 2.

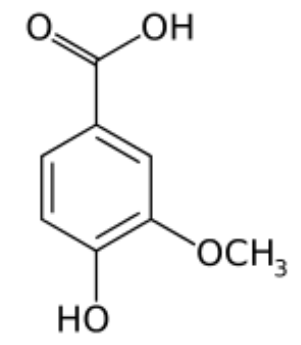

Vanillic acid

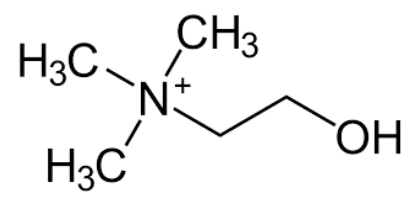

Choline

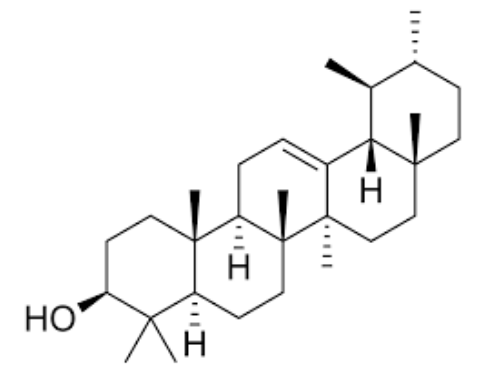

$$
\alpha \text {-amyrin }
$$

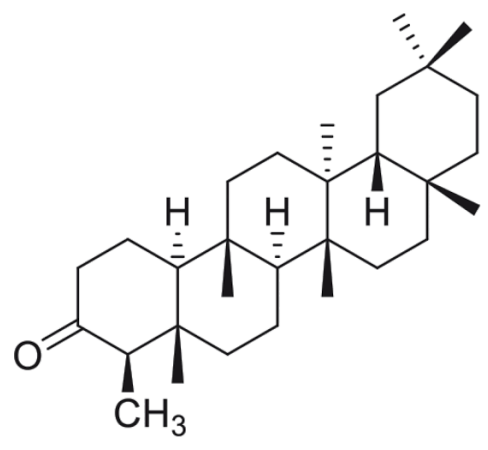

Freidelin 


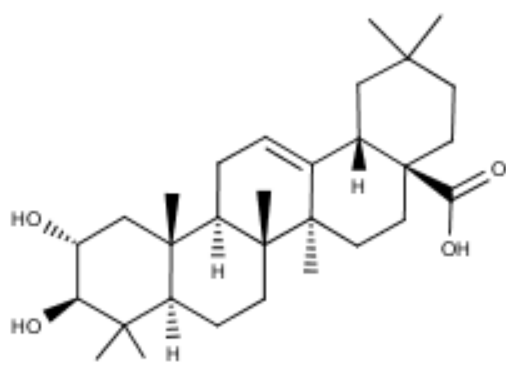

Maslinic Acid<smiles>CC[C@H](/C=C/[C@@H](C)[C@]12CC[C@H]3[C@@H]4CC=C5C[C@@H](O)CC[C@]5(C)[C@H]4CC[C@]3(C)[C@H]1C2)C(C)C</smiles>

Stigmasterol

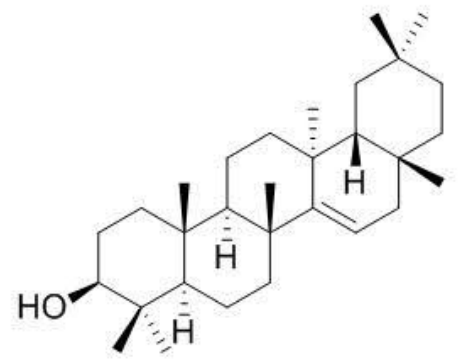

Taraxerol

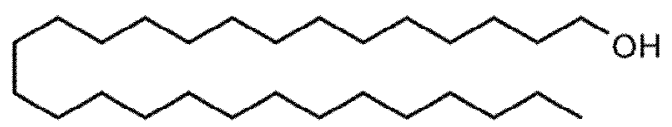

Octacosanol

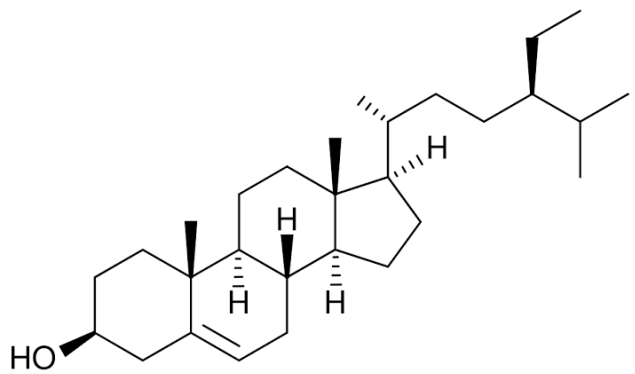

Beta-sitosterol

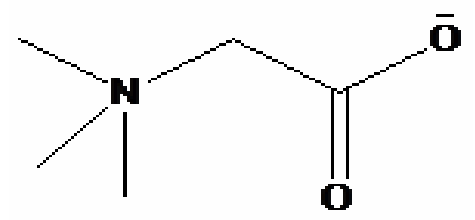

Abromine

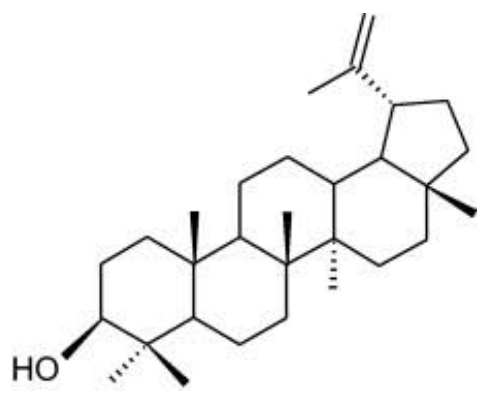

Lupeol<smiles>CCCCCCCCCCCCCC(=O)O</smiles>

Palmitic acid

Figure 2. Compounds reported from Abroma augusta.

The leaves of A. augusta contain taraxerol and its acetate, $\beta$-sitosterol acetate, lupeol, an aliphatic alcohol, octacosanal and probably a mixture of long chain fatty diols (Rastogi et al., 2003, Dasgupta et al., 1970). The stem bark of the plant contains $\beta$ sitosterol and friedelin. The presence of $\beta$-sitosterol and octacosne-1,28-diol is reported in the heatwood. The seeds of the Devil's cotton contain a fixed oil which is rich in linoleic acid having an important dietary role in the control of arteriosclerosis because of its ability to lower the cholesterol level in blood (Gupta et al., 2011). The fatty acids known to occur in A. augusta are shown in table 1.

Traditional uses: Devil's cotton has a long history of medicinal use in Ayurvedic system. It is highly beneficial in gynecological disorders. It regulates the menstrual flow and also used as abortiticient and anti-fertility agent. In India, it is used in dysmenorrhea but in Indonesia as antiinflammatory and analgesics in the treatment of 
dermatitis. The leaves and stems of A. augusta are used by the traditional healers of Bogra district but the bark of roots are known to be used by the traditional healers of Jessore district in Bangladesh. Researchers have shown the scientific support for the use of Devil's cotton in the traditional system of medicine for the treatment of type- 2 diabetes and it has the inhibitory activity of glucose absorption in the gut (Bisht et al., 2014).

Table 1. Fatty acids identified in the seed oil of $A$. augusta Linn. (Kuadkaew et al., 2010).

\begin{tabular}{|c|c|c|c|}
\hline & Fatty acids & Molecular weight & $\%$ Of whole oil \\
\hline \multirow{4}{*}{$\begin{array}{l}\text { Saturated fatty } \\
\text { acids }\end{array}$} & $\begin{array}{l}\text { n-Hexadecanoate, methyl ester } \\
\mathrm{CH}_{3}-\left(\mathrm{CH}_{3}\right)_{15}-\mathrm{CO}_{2} \mathrm{CH}_{3}\end{array}$ & 270 & 33 \\
\hline & $\begin{array}{l}\text { 2-Methyl hexadecanoate, methyl ester } \\
\mathrm{CH}_{3}-\left(\mathrm{CH}_{2}\right)_{15}-\mathrm{CH}-\mathrm{CO}_{2} \mathrm{CH}_{3}\end{array}$ & 284 & 28 \\
\hline & $\begin{array}{l}\text { n-Octadecanoate, methyl ester } \\
\mathrm{CH}_{3}-\left(\mathrm{CH}_{2}\right)_{15}-\mathrm{CO}_{2} \mathrm{CH}_{3}\end{array}$ & 298 & 13 \\
\hline & $\begin{array}{l}\text { 2-Methyl octadecanoate, methyl ester } \\
\mathrm{CH}_{3}\left(\mathrm{CH}_{2}\right)_{15}-\mathrm{CH}-\mathrm{CO}_{2} \mathrm{CH}_{3}\end{array}$ & 312 & 01 \\
\hline & $\begin{array}{l}\text { 9-Octadecnoare, methyl ester } \\
\mathrm{CH}_{3}-\left(\mathrm{CH}_{2}\right)_{7}-\mathrm{CH}=\mathrm{CH}-\left(\mathrm{CH}_{2}\right)_{7}-\mathrm{CO}_{2} \mathrm{CH}_{3}\end{array}$ & 294 & 23 \\
\hline $\begin{array}{l}\text { Unsaturated fatty } \\
\text { acids }\end{array}$ & $\begin{array}{l}\text { 10-Nonadecenoate, methyl ester } \\
\mathrm{CH}_{3}-\left(\mathrm{CH}_{2}\right)_{7}-\mathrm{CH}=\mathrm{CH}-\left(\mathrm{CH}_{2}\right)_{8}-\mathrm{CO}_{2} \mathrm{CH}_{3}\end{array}$ & 310 & 02 \\
\hline
\end{tabular}

Pharmacological values: Almost all parts of $A$. augusta is used in the treatment of various diseases. The root and root bark are reported to be useful as an emmenagogue and uterine tonic for the treatment of congestive and nervous dysmenorrhea prescribed during irregular menses (Nandkarni et al., 2002).

The leaves are reported to be useful in treating uterine disorders, diabetes, rheumatic pains of joints, and headache with sinusitis. Other uses of the plant are in stomachache, diabetes, dermatitis, and also in whitish discharge in urine in men (Rahamtullah et al., 2010).

Antidiabetic activity: Different parts like roots, leaves and barks of the plant of A. augusta are used in the treatment of diabetes. The methanolic extract and decoction of the leaves of Devil's cotton are used in the treatment of alloxan-induced diabetic rats at a dose of $300 \mathrm{mg} / \mathrm{kg}$ body weight when administered for seven days (Mishra et al., 2010; Nahar et al., 2010; Chhetri et al., 2005).

It is also effective in combined dosage form with other naturally occurring drugs like Curcuma longa and Coccinia indica for the treatment of streptozotocin (STZ) induced diabetic rats. The combined aqueous extract of A. augusta and C. longa are used in the treatment of streptozotocin $(60 \mathrm{mg} / \mathrm{kg})$ induced diabetic rats at a dose of $300 \mathrm{mg} / \mathrm{kg}$ of body weight. It is also used in combination with $C$. indica for the treatment of diabetes (Eshrat et al., 2003, Eshrat et al., 2002).

The combined aqueous extract of the leaves of $A$. augusta and Azadirachta indica (1:1) is used to treat alloxan-induced diabetic rats when administered for 8 weeks (Eshrat et al., 2003).

Antioxidant activity: The extracts were investigated for its antioxidant activity by using hydrogen donation assay method. The methanolic extract of A. augusta showed strongest antioxidant activity with $\mathrm{IC}_{50}$ value of $51.9785 \mathrm{mg} / \mathrm{ml}$. The combination of $A$. august and $C$. longa also possess antioxidant activity by inhibiting thiobarbituric acid reactive substances (TBARS) and increase in reduced glutathaione (GSH), superoxide dismustase (SOD) and catalase (CAT) (Eshrat et al., 2002; Nahar et al., 2009). 
Anti-inflammatory activity: The methanolic extract of different parts of $A$. augusta showed potent anti-inflammatory activity as compared to with the standard drug, diclofenac sodium perhaps due to the presence alkaloids and flavonoids present in the plant (Das et al., 2012).

Wound healing activity: Devil's cotton has been traditionally used for the treatment of sores. The wound healing profile of alcoholic extract of Devil's cotton and its effect on dexamethasone suppressed wound healing has been evaluated in wistar rats. (Hanif et al., 2010; Khan et al., 2003).

Hypolipidemic activity: From the experimental studies carried out by the workers showed marked decrease in lipid level in sterptozotocin-induced diabetic rats. Aqueous extract of curcumine obtained from C. longa and partially purified product from Devil's cotton. On blood glucose, lipid per oxidation (LPO) was studied for 8 weeks in Sterptozotocininduced diabetic rats. Result in total decrease in body weight, cholesterol and creatinine (Eshrat et al., 2002).

Antimicrobial activities: The $n$-hexane extract of the seeds of A. augusta has shown antifungal activity when the extract was evaluated by agar tube dilution method. Antifungal activity of the oil was tested against Trichophytons choenleinii, Pseudallescheri aboydii, Microsporum canis, Trichophyton simii (animal pathogens), Candida albican, Aspergilus niger (human pathogens), Fusarium solani, Macrophomina phaseolina (plant pathogen). Growth in the medium containing the oil was determined by measuring the linear growth $(\mathrm{mm})$ and growth inhibition (\%) was calculated with reference to the negative control. The result indicated that the seed oil of ulatkambal possesses moderate activity against human and animal pathogens but no significant activity of the extract was observed against the plant pathogens. The seed oil has the potential to be an antifungal against Trichophyton schoenleinii and Microsporum canis. The oil was also screened against various bacteria like Corynebacterium diphthereae, Escherichia coli, Klebsiella pneumoniae, Proteus morgannim, Pseudomonas aeruginosa, Salmonella typhi, Shigella boydii, Staphylococcus aureus and Streptococcus pyogenes for antibacterial activity and for insecticidal activity it has been tested against Tribolium castaneum, Ryzopartha dominica and Trogoderma granarum (Rahmatullah et al., 2010).

Phytotoxic activity: The oil extracted from the seeds of A. augusta exhibited remarkable phytotoxic activity against Lemna aeguinoctailis Welve. It was also explored to possess moderate antifungal activities against Trichophyton schoenleinii (56\%) (human pathogen) and Microsporum canis (50\%) (animal pathogen) (Khan et al., 2003).

Gynecological disturbance: The ethanolic extracts of leaves and stems of Devil's cotton are also known to be used in menstrual disorders and diseases of uterus (leucorrhoea). It shows contractile action on the uterus, and is used for the treatment of dysmenorrhea, amenorrhorea, sterility and other menstrual disorders. Powdered roots act as an abortifacient and anti-fertility agent and its petroleum-ether extract at a dose of $50 \mathrm{mg} / \mathrm{kg}$ body weight showed anti-inplantation as well as abortifacient action in mice. Significant abortifacient activity was also noticed with alcoholic and chloroform extracts. The alcoholic extract of the roots showed acetyl choline-like action, comparable to that of choline on isolated smooth and skeletal muscles. The aqueous extract of the roots showed oxytocic action. It has also been reported to possess galactotrophic effect on lactating albino rats (Gupta et al., 2011).

Thrombolytic activity: The extract of Devil's cotton was assessed for thrombolytic activity. Addition of 100- $\mu$ l Streptokinase, a positive control to the clots along with 90 minutes of incubation at $37^{\circ} \mathrm{C}$, showed $86.2 \%$ clot lysis. Clots when treated with $100-\mu l$ sterile distilled water (negative control) showed only negligible clot lysis $(5.2 \%)$. The main difference in percentage of clot lysis between positive and negative control was found to be statistically significant.

After treatment of clots with $100 \mu \mathrm{l}$ of A. augusta extract 50.1, 42.9 and $41.6 \%$ clot lysis were 
obtained. Among these clot lysis, Devil's cotton showed significant $(50.1 \%)$ clot lysis and when compared with the negative control (water) the mean clot lysis \% difference was significant. However, further study is necessary to find out the thrombolytic activity of the active compound (Bhuiya et al., 2013).

Other activity: The leaves of A. augusta have membrane stabilizing activities (Rahman et al., 2016). Ulatkambal mother tincture, a traditional homeopathic remedy is used clinically to treat people with diabetes. It is reported to have activity in managing the high blood sugar (Reddy et al., 2018). The protective effect of defatted methanol extract of Devil's cotton leaves is known against type-2 diabetes mellitus (T2DM) and its associated nephropathy and cardiomyopathy in experimental rats. Devil's cotton could offer prophylactic role against T2DM and its associated cardio-toxicity (Khanra et al., 2015).

\section{Conclusions}

In Asia, Devil's cotton is a very popular phytomedicine to the local healers. Its preparation are widely available in open areas of nature and employed by the practitioners of natural health for treatment of diabetes, infection, pain, wound healing and used as a uterine tonic. The aqueous extract of fresh leaves of Devil's cotton is popularly used by many people as an alternative treatment for type 2 diabetes mellitus by reducing the absorption of glucose, thus helps in glucose tolerance. The phytochemical screening and the reported pharmacological activities of A. augusta (Devil's cotton species) suggested the presence of valuable bioactive compounds. Therefore, extensive research should be necessary in the area of isolation and characterization of compounds from this medicinally renowned plant species. Synthetic medicines are associated with very side effects that can often cause serious problem. In the current scenario, the trend has changed from synthetic to natural medicines because of the less side effects associated with the use of natural medicines.

\section{References}

Bhuiya, M.A.M., Talukdar, B., Ajrin, M., Akter, S. and Sen, R. 2013. In vitro thrombolytic and anti-oxidant activity study of Abroma augusta (Ulatkambal). The Experiment. 14, 888-893.

Bisht, R., Bhattacharya, S. and Y. Jaliwala, Y.A. 2014. Evaluating the use of root extract of Abroma augusta as alpha glucosidase inhibitor for type-II diabetes. Annals Plant Sci. 3, 686-691.

Chhetri, D.R., Parajuli, P. and Subba, G.C. 2005. Antidiabetic plants used by Sikkim and Darjeeling Himalayan tribes, India. J. Ethnopharmacol. 99, 199202.

Das, S., Datta, R. and Nandy, S. 2012. Phytochemical screening and evaluation of anti-inflammatory activity of methanolic extract of Abroma augusta Linn. Asian Pacific J. Trop. Dis. 2, 114-117.

Dasgupta, D. and Basu, K. 1970. Chemical investigation of Abroma augusta Linn. Identity of abromine with betaine. Experientia. 26, 477-478.

Eshrat, M.H. 2002. Hypoglycemic, Hypolipidemic and antioxidant properties of combination of curcumin from Curcuma longa Linn. and partially purified product from Abroma augusta Linn. in streptozotocin induced diabetes. Indian J. Clin. Biochem. 17, 33-43.

Eshrat, M.H. 2003. Effect of Coccinia indica (L.) and Abroma augusta (L.) on glycemia, lipid profile and on indicators of end-organ damage in streptozotocin induced diabetic rats. Indian J. Clin. Biochem. 18, 54-63.

Eshrat, M.H. 2003. Lowering of blood sugar by water extract of Azadirachta indica and Abroma augusta in diabetes rats. Indian J. Exp. Biol. 41, 636-640.

Gupta, B., Nayak, S. and Solanki, S. 2011. Abroma augusta Linn f: a review. Der Pharmacia Sinica. 2, 253-261.

Hanif, A., Agarwala, B., Sarwar, S., Rahmatullah, M. and Jahan, R. 2010. Traditional use of medicinal plants in Bangladesh to treat urinary tract infections and sexually transmitted diseases. Ethnobot. Res. Appl. 8, 61-74.

Islam, T., Rahman, A. and Islam, A.U. 2012. Effects of aqueous extract of fresh leaves of Abroma augusta L. on oral absorption of glucose and metformin hydrochloride in experimental rats. ISRN Pharmaceutics. Article ID 472586, 1-5.

Khan, T., Ahmad, W., Ahmad, B., Iqbal, Z., Ahmad, M., Jan, Q. and Arfan M. 2003. Chemical composition of Abroma augusta Linn. seed oil. Pakistan J. Biol. Sci. 6, 1033-1034. 
Khan, T., Ahmad, W., Ahmad, B., Iqbal, Z., Ahmad, M., Jan, Q. and Arfan M. 2003. Biological and pharmacological propreties of Abroma augusta Linn. seed oil. Pakistan J. Biol. Sci. 6, 1142-1144.

Khanra, R., Dewanjee, S., Sahu, R., Gangopadhyay, M., Dua, T.K. and Feo, V.D. 2015. Abroma augusta L. (Malvaceae) leaf extract attenuates diabetes induced nephropathy and cardiomyopathy via inhibition of oxidative stress and inflammatory response. J. transl. med. 13, 1-14.

Kuadkaew, S. 2016. Studies on analgesic, antipyretic and anti-inflammatory activities of Abroma augusta Linn. seed oil extract in experimental animals. Prince Songkla Univ., Thailand.

Malek, M.A. 2016. Phytochemical and antimicrobial studies on the leaves extract of Abroma augusta. Khulna Univ. Engi. Technol., Khulna, Bangladesh.

Mishra, S.B., Rao, C.V., Ojha, S.K., Alok, S. and Verma, A. 2010. An analytical review of plants for antidiabetic activity with their phytoconstituents and mechanism of action. Indian J. Pharmaceut. Sci. Res. 1, 29-46.

Nahar, L., Farhana, A.R., Haque, M. and Islam, D.K.M.S. 2010. Comparative study of antidiabetic effect of Abroma augusta and Syzygium cumini on alloxan induced diabetic rat. Agricul. Biol. J. North Amer. 1, 1268-1272.

Nahar, L., Farhana, R., Rokonuzzaman, M. 2009. Investigation of antioxidant activities of six indigenous plants of Bangladesh. J. Appl. Sci. Res. 5, 2285-2288.
Nahar, N., Hazra, B.K., Mosihuzzaman, M. and Rahman, M.M. 1994. Structural studies of a mucilage from Abroma augusta root bark. Carbohyd. Poly. 24, 277 280.

Nandkarni, K.M. 1998. Indian material medica. Popular Prakashan, Bambay, 1, 1-962.

Rahamtullah, M., Nasrin, D., Momen, A. and Rahman, M. 2010. A randomized survey of medicinal plants used by folk medicine practitioners in Daudkandi subdistrict of Comilla district, Bangladesh. Adv. Nat. Appl. Sci. 4, 99-104.

Rahman, S.M.A, Rahman, M.M., Rashid. M.A. 2016. Chemical and biological investigations of leaves of Abroma augusta Linn. Bangladesh Pharm. J. 19, 233-236.

Rahmatullah, M., Bachar, S.C., Rahman, S., Jahan, R. and Nasrin, D. 2010. Brine shrimp toxicity study of different Bangladeshi medicinal plants. Adv. Nat.. Appl. Sci. 4, 163-17 3

Rastogi, R.P. and Mehrotra, B.N. 2003. Compendium of Indian medicinal plants, vol. 4.

Rastogi, RP. and Mehrotra, BN. 1990. Compendium of Indian Medicinal Plants, vol. 1.

Reddy, S.R.E., Sharma, P.K., Raj, P. 2018. Effect of Abroma augusta mother tincture in type 2 diabetes mellitus by assigning blood glucose levels - a clinical study. Inter. J. Recent Sci. Res. 9, 24687-24691. 